ORIGINAL PROF-2254

\title{
GYNAECOLOGICAL MALIGNANCIES
}

FREQUENCY AND OUTCOME AT A TERTIARY CARE HOSPITAL

\section{Prof. Dr. Tasneem Ashraf, Dr. Samia Haroon}

ABSTRACT... Objectives: To determine the frequency of different Gynecological Malignancies and outcome following primary treatment. Study Design: Cross sectional Descriptive Study. Place and Duration of study: In a tertiary care hospital; Bolan Medical Complex Hospital Quetta Baluchistan from Feb 2006 to Nov 2009. Methodology: All the women presenting with genital tract cancer during the study period were included. Their age, parity, mode of presentation, anatomic area involved, and investigations performed were noted. Stage of disease (according to FIGO staging), surgical procedures performed, and operative finding were recorded. Specimens were subjected to histopathological examination. Post operative chemo or radiotherapy was given according to stage and histopathology reports. Patients were followed up by telephonic appointments for growth recurrence, disease free interval and mortality. Follow up records were also obtained from Oncology Department \& CINAR (Cancer Institute of Nuclear Medicine and Radiotherapy) Hospital Quetta. Results: Amongst the 93 cases of gynecological cancer ovarian cancer was the commonest (45\%), cervical and uterine cancers were equal in frequency $(17.2 \%)$, and Choriocarcinoma was seen in $(9.3 \%)$ cases while vaginal cancer was rarest (1.83\%). Epithelial ovarian tumors were the commonest (71\%) and 67\% patients presented in stage III \&IV. During the median follow up period of 25 months $44 \%$ patients are alive without recurrence. $27 \%$ lost to follow up, $18 \%$ developed recurrence, $11 \%$ died with disease, $50 \%$ cancer deaths were due to ovarian cancer. Conclusions: Ovarian cancer is the commonest genital tract cancer and accounted for half of all genital tract cancer deaths. Early diagnosis and treatment can improve prognosis. Well established screening program and public awareness is important for early diagnosis and to decrease mortality.

Key words: Gynecological Malignancies, Ovarian Cancer, Cervical Cancer, Mortality, Survival rate.

Article Citation

Ashraf T, Haroon S. Frequency of gynaecological malignancies and outcome at a tertiary care hospital. Professional Med J 2013;20(5): 752-758.

\section{INTRODUCTION}

Cancer of the genital tract is a significant cause of morbidity and mortality in women worldwide. Its incidence varies from country to country due to variation in living standards, different races, ethnic taboos and environmental factors. In the United States and in countries where Pap smear screening and early treatment of cervical dysplasia is implemented, ovarian cancer is responsible for more cancer deaths each year than uterine and cervical cancer combined ${ }^{1}$. In developing countries like Pakistan, in the absence of effective screening programs cervical cancer is still a common cause of cancer morbidity and mortality ${ }^{2}$.

Ovarian cancer is the second most common gynaecologic cancer.It is the deadliest of all gynecologic cancers; ranking fourth among all causes of cancer death in women'. Ovarian cancer caused nearly 14,000 deaths in the United States alone in
$2010^{3}$. Ovarian cancer is often called the disease that "whispers" because it has few early symptoms and is most often detected in its advanced stages when it has become less treatable and widespread. Because of this, the mortality rate from ovarian cancer exceeds that for all other gynaecologic cancers combined. Approximately $70 \%$ of the women diagnosed with ovarian cancer have advanced stages of the disease ${ }^{4}$.

Endometrial cancer is the commonest uterine cancer, making up approximately $95 \%$ of all uterine cancers diagnosed. The survival rates for endometrial cancer are quite high and have steadily increased over the last 40 years since this cancer is usually diagnosed at an early stage ${ }^{5}$. There is no known cause or routine screening test for this type of cancer, therefore recognition of early symptoms such as abnormal vaginal bleeding or discharges are critical ${ }^{6}$. 
Carcinoma of the vagina is relatively uncommon affecting only $1 \%-2 \%$ of the women each year? Vaginal cancer of squamous cell carcinoma type is usually found in women between the ages of 60 and 80 and adenocarcinoma between the ages of 12 and 30 years.

In the last two decades, considerable gains have been made in the detection and treatment of these gynaecological cancers. When detected in early stages, most gynaecologic cancers have a good cure rate $^{7}$. Up till now there is no authentic data available about the incidence of different gynaecological malignancies in Baluchistan so the study was conducted to determine the frequency of different gynaecological malignancies and survival rates of different cancers.

\section{METHODOLOGY}

This cross sectional descriptive study was conducted in gynae unit IV of Bolan Medical Complex Hospital (BMCH) Quetta. It is a tertiary care hospital catering patients from all over Balochistan, border areas of Sind and Afghanistan. During the study period from Feb. 2006 to Nov. 2009 all the patients diagnosed or presented as a case of genital tract cancer were included. Patients having benign genital tract tumors were excluded from the study. Patients with malignant tumors of ovaries, uterus, Endometrium, cervix, vulva, vagina and Choriocarcinoma were included. Their addresses, telephone numbers, age, parity, mode of presentation, anatomic area involved, investigations performed, stage of disease (FIGO staging), surgical procedures performed, and operative finding were recorded. After surgery specimens were subjected to histopathological examination. Post operative chemo or radiotherapy was given according to the stage of disease and histopathology reports.

Patients were followed up by telephonic appointments for growth recurrence, disease free interval and mortality.
Follow up records were also obtained from oncology dept. of BMCH \& CINAR Hospital Quetta.

\section{RESULTS}

Total numbers of gynae admissions during the study period were 5038 while 93 patients were diagnosed as cases of gynecological malignancy. Ovarian cancer was the commonest $(45 \%)$, cervical and uterine cancers were equal in frequency (17\%), and vaginal cancer was rarest $(2 \%)$. (See figure 1 )

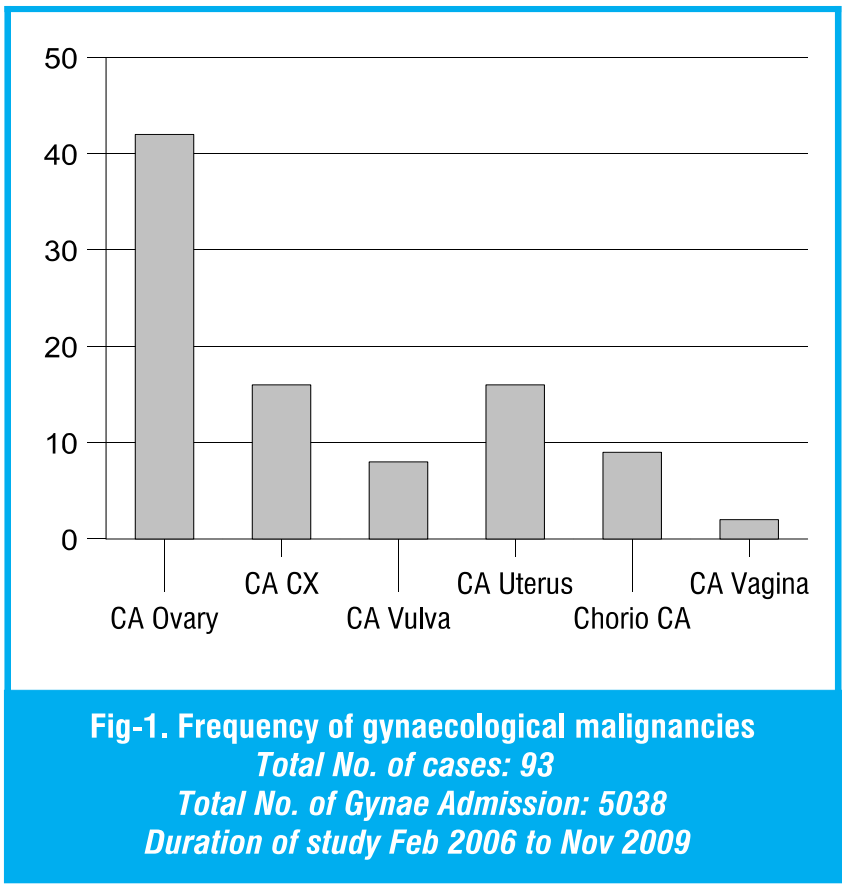

Figure 2 shows percentage of different malignancies per year. Ovarian cancer is showing slight down ward trend while uterine cancer is showing upward trend in 3 years. Mean age for ovarian cancer was 58 while mean age for cervical cancer was 59 years. (Table I)

Ovarian cancer was the most frequent cancer in our series.

$71 \%$ tumors were epithelial in origin, $12 \%$ were germ cell 7\% stromal cell and $10 \%$ were metastatic (Krukenberg) tumors.67\% patients presented in stage III \& IV and mortality in 3 years was $12 \%$. (Table II) 


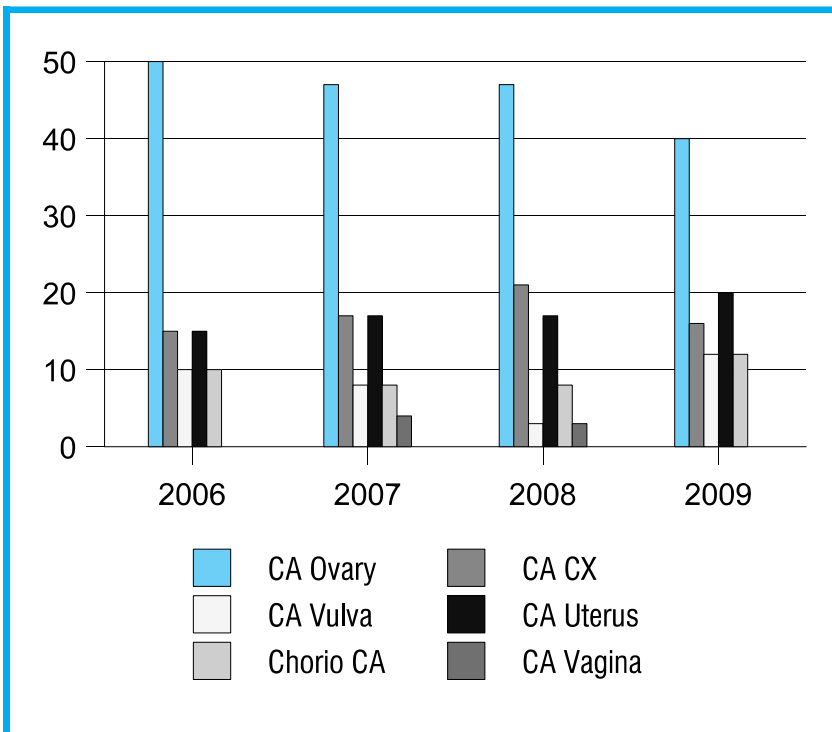

Fig-2. Percentage of gynaecological malignancies per year Total Number of Cases: 93

\begin{tabular}{|l|c|c|}
\hline \multicolumn{1}{|c|}{ Carcinoma } & Age in years & Range \\
\hline Ovarian cancer & $56 \pm 15.57$ & $18-85$ \\
\hline Cervical cancer & $59 \pm 11.03$ & $42-78$ \\
\hline Vulval cancer & $61 \pm 9.1$ & $52-70$ \\
\hline Uterine cancer & $53 \pm 7.6$ & $54-76$ \\
\hline Choriocarcinoma & $43 \pm 7.3$ & $40-56$ \\
\hline
\end{tabular}

Table-I. Mean Age of the Patients
Regarding outcome of ovarian cancer; $43 \%$ patients are alive without recurrence while $24 \%$ are alive with recurrence, $12 \%$ died with recurrence and $21 \%$ lost to follow up.

Total number of cervical cancer cases were16. All the patients under went surgery followed by radiotherapy. $56.25 \%$ patients are alive without recurrence, $12.5 \%$ are alive with recurrence $31.25 \%$ lost to follow up and no patient died of cervical cancer. (Table III)

Uterine and endometrial cancers were 17\%, 62\% patients presented in stage III \& IV. Outcome of these cancer shows that $56 \%$ patients are alive without recurrence, $12 \%$ alive with recurrence, $19 \%$ lost to follow up and $19 \%$ died of metastatic disease. (Table IV).

Vulval cancer was seen in $8.5 \%$ patients. All the patients under went surgery following that received radiotherapy. $63 \%$ are alive without recurrence, $12 \%$ died with recurrence and $25 \%$ patients lost to follow up. Summary of all cancers shows; during the median follow up period of 25 months $44 \%$ patients are alive without recurrence, $27 \%$ lost to follow up,18\% developed recurrence and11\% died with disease. Fifty percent cancer deaths were due to ovarian cancer.

\begin{tabular}{|c|c|l|c|c|l|}
\hline Stage & \% of patients & Procedure & Chemo/radio & Disease free interval & Alive / Dead \\
\hline I & (5) $12 \%$ & $\begin{array}{l}60 \% \text { pt had TAH + BSO } \\
40 \% \text { pt unilateral salpingo- } \\
\text { oophorectomy }\end{array}$ & $\begin{array}{l}\text { (3) } 60 \% \text { received } \\
\text { chemotherapy }\end{array}$ & Average 1 yr 6M & $\begin{array}{l}\text { (4) } 80 \% \text { Alive } \\
\text { (1) } 20 \% \text { lost to follow up }\end{array}$ \\
\hline II & (9) $21 \%$ & $\begin{array}{l}\text { Staging laparotomy, } \\
\text { TAH+BSO }\end{array}$ & $\begin{array}{l}\text { (7) } 78 \% \text { received } \\
\text { chemotherapy }\end{array}$ & $1 \mathrm{yrs} 2 \mathrm{M}$ & $\begin{array}{l}\text { (7) } 78 \% \text { Alive } \\
\text { (2) } 22 \% \text { lost to follow up }\end{array}$ \\
\hline III & (16) $38 \%$ & $\begin{array}{l}\text { Staging laparotomy, } \\
\text { TAH+BSO \& optimal } \\
\text { debulking }\end{array}$ & $\begin{array}{l}100 \% \text { received } \\
\text { chemotherapy }\end{array}$ & 9 Months & $\begin{array}{l}\text { (10) } 62 \% \text { Alive } \\
\text { (3) } 19 \% \text { lost to follow up } \\
\text { (3) } 19 \% \text { dead }\end{array}$ \\
\hline IV & (12) $29 \%$ & $\begin{array}{l}\text { Staging laparotomy \& } \\
\text { optimal debulking }\end{array}$ & $\begin{array}{l}\text { (9) } 75 \% \text { received } \\
\text { Chemo / } \\
\text { Radiotherapy }\end{array}$ & 6 Months & $\begin{array}{l}\text { (7) } 58 \% \text { Alive } \\
\text { (2) } 17 \% \text { Died } \\
\text { (3) } 25 \% \text { lost to follow up }\end{array}$ \\
\hline
\end{tabular}




\begin{tabular}{|c|c|c|c|c|}
\hline \multicolumn{5}{|c|}{$\begin{array}{c}\text { Table-II. Outcome of ovarian cancers } \\
\text { Total no. of cases: 42 }\end{array}$} \\
\hline Stage & $\%$ of patients & Procedure & Chemotherapy/ Radiotherapy & Fate \\
\hline I & None & - & - & - \\
\hline II & $(6$ pt) $38 \%$ & $\begin{array}{l}\text { EUA + Biopsy / Radical } \\
\text { hysterectomy }\end{array}$ & Received Radiotherapy & $\begin{array}{l}\text { (5) } 83 \% \text { Alive without recurrence } \\
\text { (1) } 17 \% \text { No follow up }\end{array}$ \\
\hline III & (7) $44 \%$ & EUA + Biopsy & Radiotherapy completed & $\begin{array}{l}\text { (4) } 58 \% \text { Alive without recurrence } \\
\text { (2) } 28 \% \text { Alive with recurrence }\end{array}$ \\
\hline IV & $(3) 19 \%$ & EUA + D\&C \& Biopsy & Radiotherapy not completed & (3) No follow up
\end{tabular}

\begin{tabular}{|c|c|l|l|c|l|}
\hline Stage & $\%$ of patients & \multicolumn{1}{|c|}{ Procedure } & \multicolumn{1}{|c|}{$\begin{array}{c}\text { Post-operative } \\
\text { treatment }\end{array}$} & $\begin{array}{c}\text { Disease free } \\
\text { interval }\end{array}$ & \multicolumn{1}{|c|}{ Follow up } \\
\hline I & (3 pt) $19 \%$ & $\begin{array}{l}\text { Staging Laparotomy \& } \\
\text { TAH + BSO }\end{array}$ & $\begin{array}{l}\text { No post-operative } \\
\text { treatment }\end{array}$ & $2 \mathrm{yrs}$ & (3) $100 \%$ Alive \\
\hline II & (3) $19 \%$ & $\begin{array}{l}\text { Staging Laparotomy \& } \\
\text { TAH + BSO }\end{array}$ & $\begin{array}{l}\text { 2 Patient received } \\
\text { radiotherapy }\end{array}$ & $1 \mathrm{yrs} 4 \mathrm{M}$ & $\begin{array}{l}\text { (2) } 67 \% \text { Alive } \\
\text { (1) } 33 \% \text { No follow up }\end{array}$ \\
\hline III & (8) $50 \%$ & $\begin{array}{l}\text { TAH + BSO partial } \\
\text { omentectomy }\end{array}$ & $\begin{array}{l}\text { (6) } 75 \% \text { patient } \\
\text { received chemo / } \\
\text { radiotherapy }\end{array}$ & $1 \mathrm{yr}$ & $\begin{array}{l}\text { (5) } 63 \% \text { Alive } \\
\text { (2) } 25 \% \text { No follow up } \\
\text { (1) } 12 \% \text { dead }\end{array}$ \\
\hline IV & (2) $12 \%$ & $\begin{array}{l}\text { TAH + BSO optimal } \\
\text { debulking }\end{array}$ & $\begin{array}{l}\text { 100\% patient received } \\
\text { chemo/radiotherapy }\end{array}$ & $<6$ Months & $\begin{array}{l}\text { (1) } 50 \% \text { Died of complication } \\
\text { (1) } 50 \% \text { Alive with disease }\end{array}$ \\
\hline
\end{tabular}

\section{DISCUSSION}

In our study ovarian cancer was the commonest among cancers of genital tract it constituted $45 \%$ of all cancer cases. Some other studies from Pakistan have also shown that ovarian cancer is the commonest rather than the cervical cancer ${ }^{9,10,11}$. Cervical and endometrial cancers ranked second in our study which is rated third most frequent malignancy in females by Karachi cancer registry ${ }^{12}$. According to Hanif et al, institution based data 2009 ovarian cancer is the third most common cancer after cancer of breast and oral cavity ${ }^{13}$. The reason for the relatively high rates of the cancers of the ovary in Pakistan are not known. Life style and reproductive factors may influence the incidence of breast and ovarian cancer. Decreasing frequency of cervical and increase in uterine and ovarian cancer rate in our study can not be explained, though we do not have proper screening programs for cervical cancer. Injudicious use of HRT and ovulation induction drugs 
may be responsible for increasing frequency of uterine and ovarian cancers respectively.

In developing countries of Asia and Africa Cervical cancer is the commonest cancer and one of the leading causes of morbidity and mortality amongst the gynaecological cancers ${ }^{14}$. Studies from India and African countries proved the fact that cervical cancer is the commonest in their series ${ }^{15,16,17}$. While in the studies from UK and European countries endometrial cancer is the most frequent cancer ${ }^{18,19}$.

The mean age for cervical cancer in our study is higher than the age in other studies in Pakistan ${ }^{10,11}$. It may be related to environmental, racial or genetic factors. In our study cervical cancer was 17\%. Low incidence of cervical cancer in our study is comparable with another study in Karachi Pakistan ${ }^{12}$.

Ovarian cancer can occur at any age, even in childhood, but is most common after menopause. In our series mostly patients were in post menopausal age. The disease accounts for about 20,000 new cases and 12,500 deaths in the United States annually ${ }^{20}$. Ovarian cancer usually has a poor prognosis. It is disproportionately deadly because it lacks any clear early detection or screening test, meaning that most cases are not diagnosed until they have reached advanced stages. More than $60 \%$ of women presenting with this cancer have stage III or stage IV cancer, when it has already spread beyond the ovaries $^{21}$. While the overall five-year survival rate for all cancers combined has improved significantly: $68 \%$ for the general population diagnosed in 2001 (compared to $50 \%$ in the 1970 s), ovarian cancer has a poorer outcome with a $47 \%$ survival rate (compared to $38 \%$ in the late 1970s) ${ }^{22}$.

The five-year survival rate for all stages of ovarian cancer is $47 \%$. For cases where a diagnosis is made early in the disease, when the cancer is still confined to the primary site, the five-year survival rate is
$92.7 \%^{22,23}$.

In our series overall ovarian cancer survival rate was $54 \%$ it is comparatively lower than the results of Ayhan $A$, and Trimbos ${ }^{23,24}$. Reason for low survival rate can be explained as in our patients all the surgeries were done by gynecologist instead of Gynecological Oncologist and lack of frozen section facility so extensive lymph node dissection was not done and mostly patients received adjuvant radio or chemotherapy.

According to Mahnev ${ }^{25}$ systematic pelvic and Paraaortic lymph node dissection in early stage ovarian cancer can improve survival. But few other multicentre studies showed improved survival in all stages of ovarian cancer by using adjuvant chemotherapy following optimal debulking surgery ${ }^{26,27}$.

Cancer deaths were mainly (50\%) due to ovarian cancer in our study. In European countries and UK, ovarian cancer deaths were also highest where mortality from ovarian cancers in 2007 was 9.8 $/ 100,000$ and from uterine cancer was $3.4 / 100,000$ women/yr ${ }^{4}$.

Endometrial cancer 5year survival rates in a study by Jing Wang in 2008 was $80 \%-95 \%, 75 \%, 50 \%$ and $20 \%$ for stage I, II, III and IV disease ${ }^{5}$. In our study during 25months follow up survival rates for endometrial cancer for these stages were $100 \%, 67 \%, 62 \%$ and $25 \%$ respectively.

The prognosis of endometrial cancer is generally favourable because in $75 \%$ to $90 \%$ of cases the disease is confined to the uterus at diagnosis, a condition that is highly curable by surgical removal of the uterus ${ }^{28}$. The overall five-year survival rate is $75 \%$. In addition to stage at diagnosis, survival from endometrial cancer is also greatly influenced by histological type and grade of the tumour. While over the past 30 years there has been no appreciable improvement in survival among women with 
advanced disease ${ }^{27}$.

Stage at diagnosis, hormonal and reproductive characteristics, socio-economic level and access to health care make the difference in survival rates.

\section{CONCLUSIONS}

Ovarian cancer is the major killer among all genital tract cancers. Early diagnosis can improve prognosis in all type of gynecological cancers. Well established screening program and Public awareness is important for early diagnosis.

Multidisciplinary approach can provide better care. Gynecological Oncology unit should be established in all tertiary care hospitals to get best results of treatment. Team consisting of: Gynecological oncologist, Medical oncologist, Histopathologist and Radiological oncologist should work in collaboration.

Close follow up of patients should be maintained in order to detect residual disease or early recurrence for better survival.

\section{Copyright@ 28 May, 2013.}

\section{REFERENCES}

1. "Ovarian Cancer". The Merck Manual for Healthcare Professionals. November 2008. http://www.merckma nuals.com/professional/sec19/ch269/ch269b.html.

2. Faizan S, Ayub S, Manzoor N, et al. Knowledge and Awareness about Cervical Cancer and its Prevention: PLoS One. 2010; 5(6): e11059.

3. UK ovarian cancer incidence statistics: cancer research UK 2009. Gynecol oncol 2009;20:67-71.

4. Goff, BA. "Ovarian cancer: screening and early detection. Obstetrics and gynecol clinic of North America .2012;39 (2): 183-94.

5. Jing Wang Chiang. Uterine Cancer. e Medicine Obstetrics and gynecology 2009.

6. Howlader N, Noone AM, Krapcho M, Neyman N,
Aminou $R$, Waldron W, SEER Cancer Statistics Review, 1975-2008, National Cancer Institute. Bethesda, MD, ttp://seer.cancer.gov/csr/1975 2008.

7. Lorenzo Gafa, Pasquale Amendola. Cancers of female genital tract in Raguasa, Sicily. European $\mathrm{J}$ of Epidemiology 1995; 11:443-446.

8. Survival rates based on SEER incidence and NCHS mortality statistics, as cited by the National Cancer Institute in SEER Stat Fact Sheets - Cancer of the Ovary.

9. Bhurgri $Y$, Bhurgri $A$, Rahim $A$ et al. The pattern of malignancies in Karachi (1995-1996). J Pak Med Assoc 1999; 49: 157-61.

10. Nasreen F. Pattern of gynaecological malignancies in tertiary hospital. Journal of postgraduate Medical institute Peshawar. 2002; 16 № 2:215-220.

11. Aziz Z, Sana S, Saeed S, Akram M. Institution based tumour registry from Punjab: five years data base analysis. J Pak Med Assoc 2003; 53: 350-352.

12. Yasmin B, Kauser N, Yasmeen S. Patho- epidemiology of cancer cervix in Karachi South. Asian Pacific $J$ of cancer prevention 2007; 8:357-362.

13. Hanif $M$, Zaidi $P$ et al. Institution based cancer incidence in a local population in Pakistan: Asian Pacific Journal of cancer prevention. 2009;10:227230.

14. Hamer MJ, Ries LA, Krapcho M. SEER Cancer Statistics review 1975-2006; National cancer institute Bethesda.

15. Chhabra S, Sonak M, Prem V. Gynaecological malignancies in a rural institute in India. J. Obstet. Gynaecol 2002; 22(4):426-9.

16. Kyari 0 , Nggada $\mathrm{H}$. Malignant tumors of female genital tract. East African medical J 2004; 81 No.3:142-145.

17. Galadanci HS, Mohammed AZ, Uzoho CC, Jido TA, Ochicha 0 . Gynaecological malignancies seen in a tertiary health facility in Kano, Northern Nigeria. Trop J Obstet Gynaecol 2003; 20: 105-8.

18. "WHO Disease and injury country estimates". World 
Health Organization. 2009. Retrieved November 11, 2009.

19. Evans T, O Sany, P Pearmain, R Ganesan, A Blann and $S$ Sundar. Differential trends in the rising incidence of endometrial cancer by type: British Journal of Cancer 2011; 104, 1505-1510.

20. "Ovarian Cancer". http://emedicine.medscape.com/ article/255771-overview. Retrieved July 27, 2010.

21. Stephen A. Cannistra, M.D Cancer of the Ovary. N Engl J Med 2004; 351:2519-2529 December 9, 2004.

22. Johannes, Laura (March 9, 2010). "Test to Help Determine If Ovarian Masses Are Cancer". The Wall Street Journal.

23. Ayhan A, et al. Occult metastasis in early ovarian cancer; Risk factors and associated prognosis. Am J Obstet Gynecol 2007; 196: e1-81.e6.
24. Trimbos JB, Vergote I, Bolis G, et al. Impact of adjuvant chemotherapy and surgical staging in ovarian cancer. J Na H Cancer Inst. 2003,95:113-25.

25. Mahnev S, Reuss ,Pujade-Lauvaine. Complete surgical debulking in advance ovarian cancer improve prognosis in any FIGO stage. University medical centre Hamburg Eppendrof Germany.2009; S 254: xix FIGO world congress.

26. Bristow RE, Tomacruz RS. Survival effect of maximal cytoreductive sugary for advance ovarian cancer during the platinum era: J Clin Oncol 2002; 20:1248-59.

27. Aletti GD, Long $\mathrm{HJ}$, Cliby WA. Is time to chemotherapy a determinant of prognosis in ovarian cancer? Gynaecol Oncol 2007; 104:212-6.

28. Irvin WP, Rice LW, Berkowitz RS: Advances in the management of endometrial adenocarcinoma: a review. J Reprod Med 2002, 47:173-190.

\section{AUTHOR(S):}

1. Prof. Dr. Tasneem Ashraf

Head of Gynae Unit-IV

Bolan Medical Complex Hospital,

Quetta.

2. Dr. Samia Haroon

Postgraduate FCPS-II (PGR-III)
Correspondence Address:

Prof. Dr. Tasneem Ashraf

Room No. 5 \& 6 1st Floor Saleem Medical Complex,

Jinnah Road, Quettaa

shraftasneem55@gmail.com

Article received on: 17/04/2013

Accepted for Publication: 28/05/2013 Received after proof reading: 18/09/2013

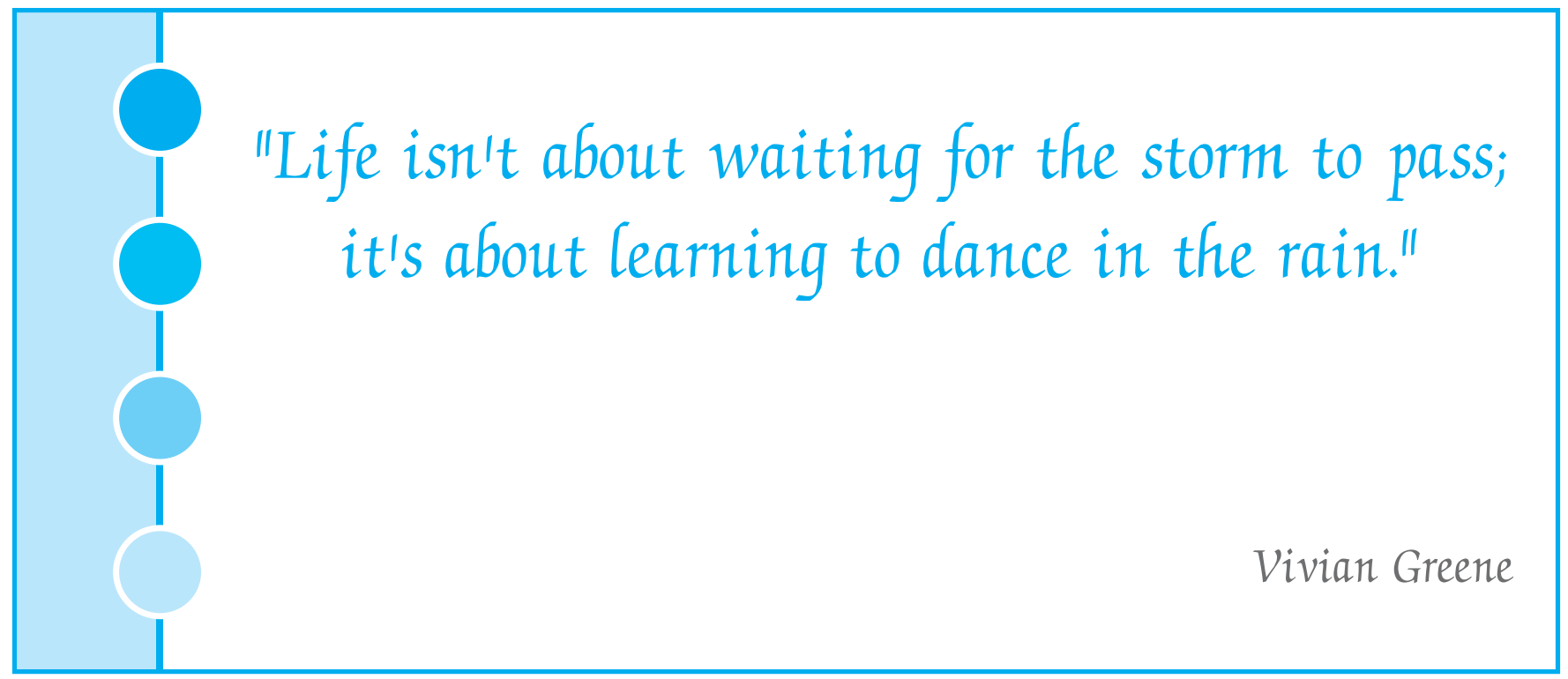

